\title{
The research on fatigue test of the pin for the folded arm lorry crane
}

\author{
MA Hong-feng ${ }^{1, a}$, YUAN Zheng-wen ${ }^{1, b^{*}}$ and GAO Le $\mathrm{L}^{1, \mathrm{c}}$ \\ 1Jiangsu Xuzhou Construction Machinery Institute of XCMG, Xuzhou 221004, China \\ amhfxyq@163.com, byzwysu@ysu.edu.cn, ${ }^{\mathrm{c}}$ leqing2009@163.com
}

Keywords: Fatigue; The folded arm lorry crane; Pin; Quench

Abstract. Based on the structure mechanics analysis and fatigue mechanism study for the pin of the folded arm lorry crane, a new fatigue test equipment for the pin of the folded arm lorry crane is developed. The pins are quenched in different hardened layer depth ratio, and then 48 pins are chosen for the fatigue test. According to the test result, the theory that the pin hardened layer depth ratio over $10 \%$ will improve the fatigue life is certified. For the material of $42 \mathrm{CrMo}$, diameter of $60-80 \mathrm{~mm}$, the effect of the hardened layer depth ratio on the pin fatigue life is analyzed, and the best hardened layer depth ratio is about $12 \%$.

\section{Introduction}

Folded arm lorry crane is one type of the lorry crane, which is a special machinery to lift and turn weights. Arm structure of lorry crane is complex, which has an excellent mechanical property, and the performance of the arm structure is the key point in the overall performance [1]. In the whole structure of the arm, the pin is one of the important parts, which can connect parts and transfer loads. During the work, the pin mainly bears shear and bending loads. In the concrete lifting process, alternating load is produced between the arm and pin. Under the alternating load, the pin is subjected to cyclic shear and bending load. The fatigue life of pin depends on its material impact strength and toughness and so on.

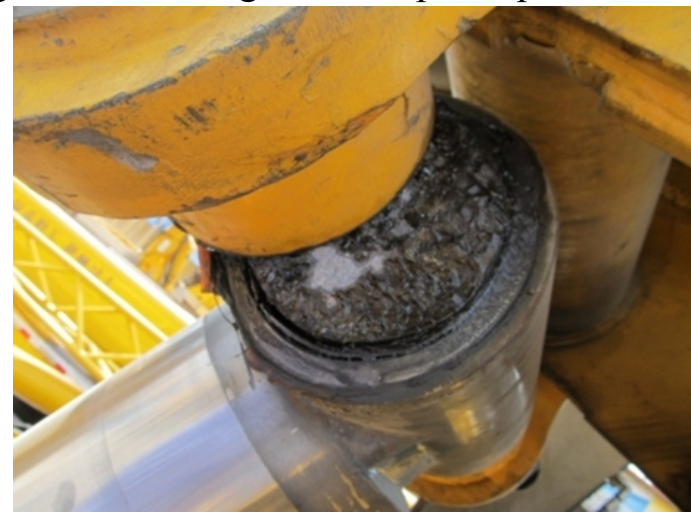

Fig. 1 Fatigue of the pin on lorry crane

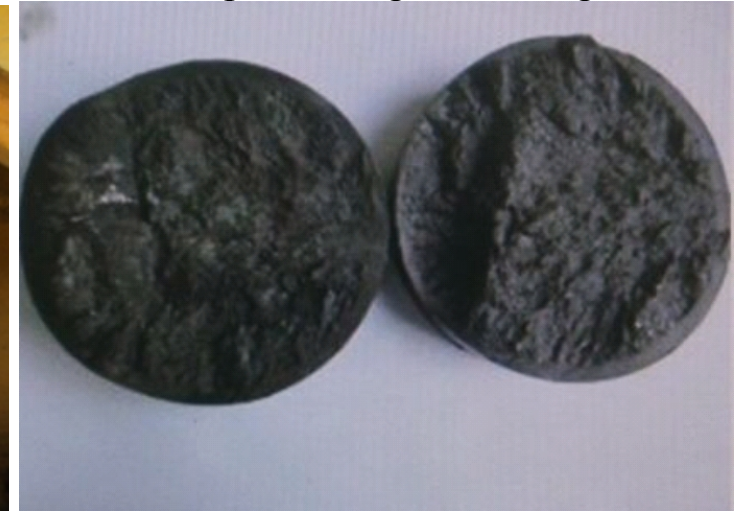

Fig. 2 Fatigue surface of the pin

In order to improve the fatigue life of the pin, some researchers have taken some research in the past years. Based on the load distribution of the pin, CHEN and LI[2] analyzed pin's failure mechanism, a new pin is designed by the theory of high-cycle fatigue stress ratio method. YAN et al.[3] analyzed pin of bridge, after validation of the contact parameters of finite element model, the contact stress in pinned connection of the Bridge in support dismantling condition was computed. Through the stress values measured in the field, the computed results can correctly reflect the magnitude and distribution of contact stress in comparison, which proved the reliability of finite element model. To the pin of the bridge as the research object, some scholars obtained similar conclusions [4-6].

The studies above were analyzed from the pin design and media of the surface heat treatment to improve the fatigue life of the pin. However, the fatigue failure of the pin is a complex problem caused by multiple factors, not only with the working condition, the structure mechanical properties of the pin, but also associated with the surface treatment. In this paper, the fold lorry crane arm pin will be studied. Based on the quenching test on $35 \mathrm{CrMnSiA}$ pin, WANG [7,8] studied the effects of different quenching media for the mechanical properties of $35 \mathrm{CrMnSiA}$ pin, for selecting the best quenching 
media for the heat treatment. This paper detailed study and discuss the effect of different hardened layer depth to the pin's fatigue. And it will provide the basis for improving the designing fatigue life of the pin.

\section{The fatigue mechanism of the pin}

Due to squeeze each other at the hinge and the relatively large force, a tiny dislocation on the contact surface will be happened, and mating surface asperity welding and fracture continue to occur. Under the vertical load and cyclic shear stress, oxide film on the contact surface be ruptured, which will produce a strong adhesion between the metals. In this case, if the shear stress loop cannot make the welding area separate, the welding point will be distributed over a larger area, so the edge of the welding area will generate high stress concentration. As the result, the fatigue crack will be generated. And after adjacent micro cracks congest, which will make bonded asperity rupture, and pitting on the metal surface will migrate from one surface to another. In this case, local high temperature will generate and oxidize small pieces of broken metal to form oxide particles. For most metals, these oxide particles are harder than the metal itself, and when they fall between mating surfaces, abrasive wear and scratches will be caused. In fretting alternating deformations, the process above is repeated, so that the crack expend, fatigue strength decreases and which will cause the bad fit between two surfaces. As the result, the pin fatigue happens [1].

In order to improve the fatigue life of the pin, a method is increasing the strength of the pin surface, which can be realized by the heat treatment method. Proposed in the literature[9], hardening depth of more than $10 \%$ of the radius of the pin, fatigue life of the pin can be improved, but the extent of this method did not improve. In this paper the effect of pin diameters, depth of hardened layer on the fatigue life of the pin will be analyzed, and the pin of a mini type folded arm lorry will be taken as an example to make a specific analysis.

\section{The fatigue test of the pin}

The main materials of the pin for lorry crane are $42 \mathrm{CrMo}, 40 \mathrm{Cr}$. In this experiment, $42 \mathrm{CrMo}$ is chosen, and the pins of ordinary diameters $60 \mathrm{~mm}, 70 \mathrm{~mm}, 80 \mathrm{~mm}$ on folded arm lorry crane are taken, the length is $400 \mathrm{~mm}$. The test pins are processed from the same factory, the same batch, the same process equipment. Before the test, the pin surfaces were cleaned, and the scratches on pin surface are checked. Hardening test machine is applied for the pins of each diameter group separately in different hardened layers depth ratio of $8 \%, 9 \%, 10 \%, 11 \%, 12 \%, 13 \%, 14 \%, 15 \%$. After the quality check, 48 pins are chosen for the fatigue test. There are 2 pins for each diameter and each hardened layer depth respectively.

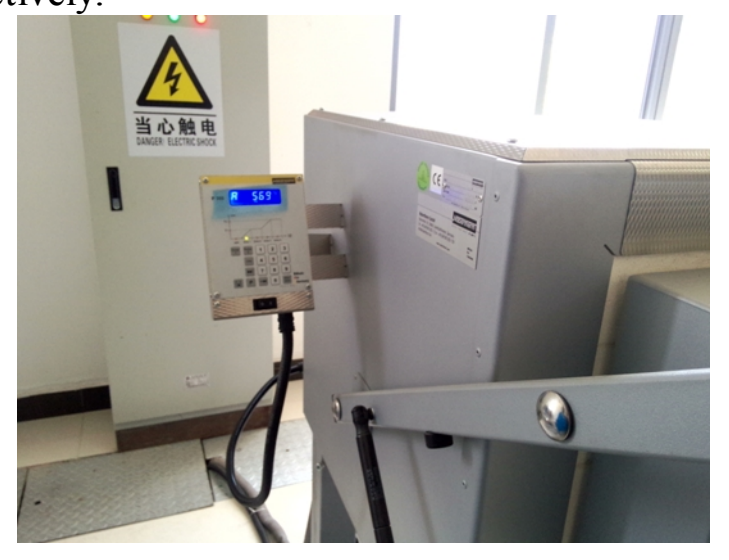

Fig. 3 Quench machine

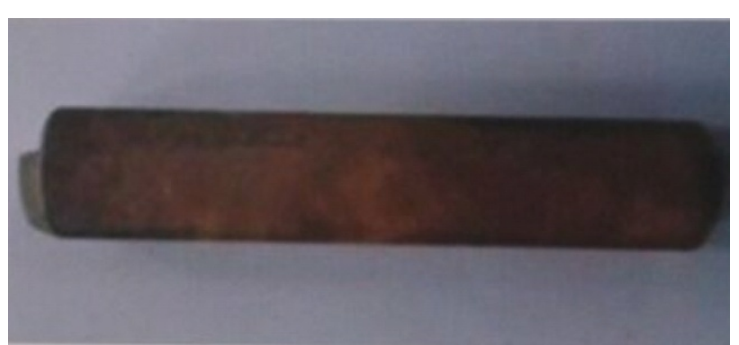

Fig. 4 Tested pin sample

The pins after hardening were taken for fatigue test, and US MTS fatigue testing machine is chosen, performance parameters (load $0-200 \mathrm{kN}$, frequency range $0-100 \mathrm{~Hz}$ ), the frequency of the 
fatigue test for the pins was $0.5 \mathrm{~Hz}$. In this fatigue test, the alternating load is $650 \mathrm{kN}$, and three fatigue test equipment are used in this test. After 11 months, the fatigue test is finished.

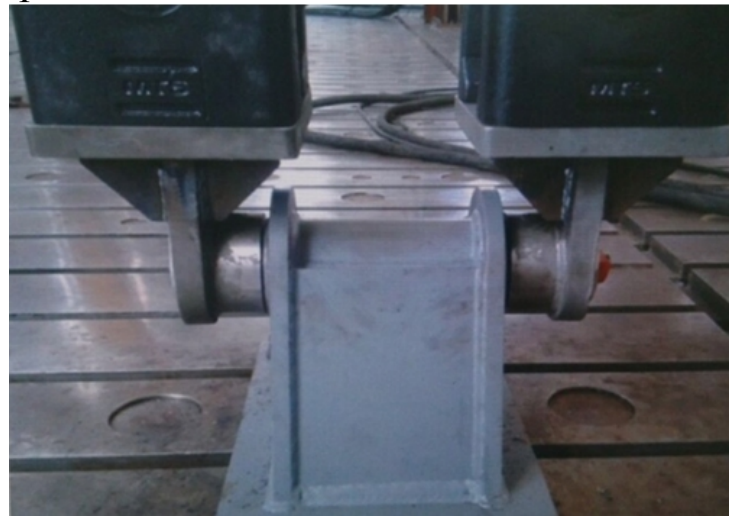

Fig. 5 Fatigue test equipment

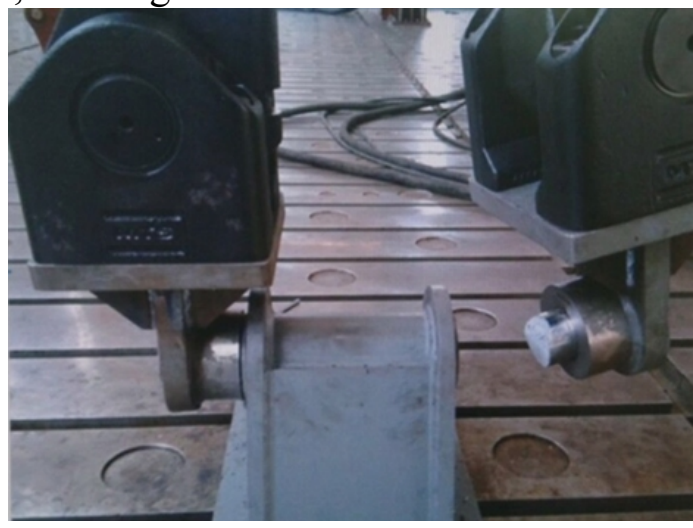

Fig. 6 Fatigue of the pin

\section{Result and analysis}

The test results are shown as Fig 7. It is concluded that the fatigue life of the pin will increase with the increasing depth of hardened layer with the same alternating load and the same diameter. But the fatigue lives of the pin begin to decrease when the quenching depth of the pin continues to increase from $12 \%$. And this law will be still with the change of the diameter and alternating load.

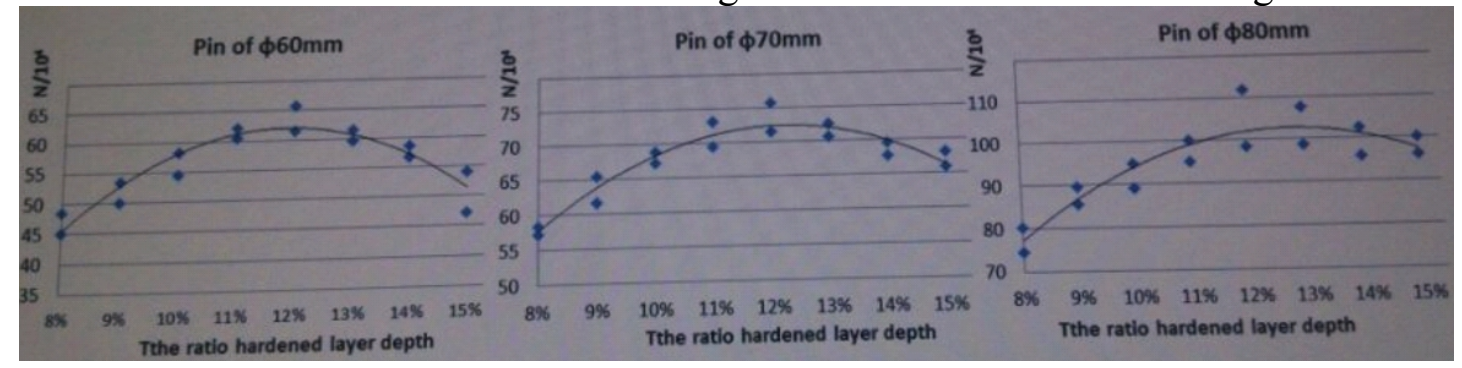

Fig. 7 The effect of hardened layer depth ratio on the pin fatigue life

Based on the theoretical analysis, it is found that the metal microstructure will be changed with the surface hardening treatment, supercooling austenite is transformed to martensite gradually, which can improve the surface characteristics of the metal greatly. These treatments for fatigue life pin within a certain range are effective. However, with the depth of hardened layer increased further, the overall toughness of the pin will reduce, the fatigue resistance and fatigue life will decrease. In this paper, the hardening and fatigue tests of the pin validate this theory. And quantitatively given for materials $42 \mathrm{CrMo}$, small diameter $50-70 \mathrm{~mm}$ hinge pin knuckle boom cranes, the best hardening depth ratio to improve the fatigue life is $12 \%$.

\section{Conclusion}

Based on the fatigue mechanism and test study for the pin of the folded arm lorry crane, the conclusions are as follows:

(1) Based on the fatigue mechanism and test of the pin, it is concluded that the theory that the pin hardened layer depth ratio over $10 \%$ will improve the fatigue life is certified.

(2) For the pin of the folded arm lorry crane, material as $42 \mathrm{CrMo}$, and the diameters as $60-80 \mathrm{~mm}$, the best hardened layer depth ratio is about $12 \%$. 


\section{References}

[1] G.G. Chen, L.X. Hua, S.H. Wang. Ways to improve fatigue life of pin roll for cantilever crane[J]. HEAT TREATMENT OF METALS, 37(2012):124-127. (in Chinese)

[2] Z.Y. Chen, E.M. LI. Failure Mechanism Analysis and Anti Fatigue Design on the Articulation Pin[J]. Construction machine technology and manager, 7(2014): 104-106. (in Chinese)

[3] D.H. Yan, X.F. Liu, Z.C. Tian, T. Peng. Contact Stress Analysis of Pinned Connection[J]. ENGINEERING MECHANICH, 25(2008): 15-20. (in Chinese)

[4] K. Iyer. Solution for contact in pinned connections[J]. International Journal of Solids and Structure, 38(2001):9133-9148.

[5] M. Ciavarella, P. Decuzzi. The state of stress induced by the plane frictionless cylindrical contact in the case of elastic similarity[J]. International Journal of Solids and Structures, 38(2001):4507-4523.

[6] Q.K. Liu, S.Z. Qiang, Q. Zhang. Structural analysis of ear-plate cable and beam anchorage for cable-stayed bridge[J]. China Journal of Highway and Transport, 15(2002):72-75. (in Chinese)

[7] Q.K. Liu, X.M. Wang, S.Z. Qiang. Full scale model test on anchorage zone of the second Yangtze River bridge at Nanjing[J]. China Civil Engineering Journal, 34(2001):50-54. (in Chinese)

[8] L.R. Wang, F.H. Jia, Y.N. Zhang. Study of Quenching Process for 35CrMnSiA Articulation Pin[J]. Mechanical Engineer, 12(2011): 138-139. (in Chinese)

[9] D.X. Cheng. Mechanical Design Handbook[M]. Chemical industry press, Beijing, 2007, pp. 200-210. (in Chinese) 